\title{
Introduction: Moral Emotions
}

\author{
Florian Cova ${ }^{1} \cdot$ Julien Deonna $^{2} \cdot$ David Sander $^{3}$
}

Published online: 2 September 2015

(C) Springer Science+Business Media Dordrecht 2015

\section{What Makes Emotions Moral?}

The claim that the psychological study of morality underwent a revolution at the beginning of the twenty-first century and that this revolution was an affective one is now commonplace: emotions, rather than reflection and reasoning from explicit moral principles, were suddenly supposed to play the prominent role in moral thought and behaviour (Haidt 2001, 2007). Though supporters of this revolution might crudely underestimate the importance other fields — such as philosophy — had already allocated to emotions in moral thinking and behaviour, there is no denying that this change of attitudes within psychology has had such an impact that it has affected other disciplines such as philosophy, neuroscience and sociology and has led

Florian Cova

florian.cova@gmail.com

Julien Deonna

Julien.Deonna@unige.ch

David Sander

David.Sander@unige.ch

1 Swiss Centre for Affective Sciences, University of Geneva, Campus Biotech, Uni Dufour, Rue Général Dufour 24, 1211 Genève 4, Switzerland

2 Department of Philosophy and Swiss Centre for Affective Sciences, University of Geneva, Campus Biotech, Case Postale 60, 1211 Genève 20, Switzerland

3 Department of Psychology and Swiss Centre for Affective Sciences, University of Geneva, Campus Biotech, Uni Dufour, Rue Général Dufour 24, 1211 Genève 4, Switzerland researchers throughout these fields to pay more attention to the role emotions play in everyday morality.

One consequence of this renewed interest in the interplay between emotions and morality was a sudden increase in the use of the expression "moral emotions" (see for example: De Sousa 2001; Haidt 2003; Tangney et al. 2007; Mulligan 2008). Though this expression is now widespread-and this surely reflects the general realization that emotions matter for morality-, it is still debated what counts as a "moral emotion" and what emotions should be considered "moral". Haidt (2003) tentatively defined moral emotions as "those emotions that are linked to the interests or welfare either of society as a whole or at least of persons other than the judge or agent."(p. 853) However, such a definition leaves unexplained the crucial problem of the exact "link" between emotions and morality and arbitrarily restricts the field of morality (excluding, for example, possible moral duties towards oneself). So, what kinds of "link" are there between emotions and morality, and which ones are relevant for a satisfactory characterisation of moral emotions?

It is now widely accepted that emotions present their object (their "intentional object") in a certain evaluative way (e.g. De Sousa 1987 and Deonna and Teroni 2012 for a thorough overview of what this claim may mean). Thus, fear presents a certain object as dangerous. The value that an emotion presents its object as instantiating is this emotion's "formal object". Thus, some emotions might be said to be moral in virtue of their "formal object", that is: because they present their object as instantiating a certain moral value (e.g. Mulligan 2008). For example, some consider that guilt presents the person who feels it as responsible for a transgression or wrongdoing, and others consider indignation as a particular brand of anger that presents a certain act as being unjust. In this first sense, an 
emotion is moral when it presents its object as having some moral value (or disvalue). ${ }^{1}$

In a related (albeit different) sense, emotions can be considered as "moral" to the extent that they provide us with an epistemic access to certain moral facts (or, at least, play an important role in the formation of our moral evaluations). Indeed, not only certain emotions present their objects with a certain moral value, but some have proposed that emotions constitute a privileged way by which we come to know (or believe) that these objects have such and such value (e.g. Tappolet 2000). Of course, whether moral evaluations trigger moral emotions or are informed by them is an ongoing debate within philosophy and psychology (see for example: Huebner et al. 2009).

In a third and still different sense, emotions are moral because they motivate us to act morally (for such a use of the expression, see e.g. Tangney et al. 2007). Indeed, emotions are a powerful source of motivation and some have even argued that they constitute a necessary condition for moral beliefs to translate into the corresponding action (Damasio 1994). For example, compassion motivates us to help those who suffer and guilt drives us to repair the harm we have done. Even those who deny that emotions are moral in the two previous senses can (and should) acknowledge the motivational power of emotions, for affective phenomena do not have to present their object in a moral light to motivate moral behaviour. For example, love can motivate us to help others without presenting them as instantiating any moral value (though it definitely presents them as instantiating certain values; see Naar 2013).

In a fourth sense, it is possible to think of certain emotions as "moral" insofar as their cultivation within a certain individual or society contribute to fostering morality within this very same individual or society. From this standpoint, an emotion's moral pedigree is not determined on the basis of its intrinsic properties (what it is directed at, what it motivates us to do), but on the basis of their effects at the level of an individual's life or of whole human societies. This is how, for example, Tangney et al. (2007) must be interpreted when they write that, when compared with shame, "empirical researches suggest that guilt, on balance, is the more moral or adaptive emotion. Guilt appears to motivate reparative action, foster otheroriented empathy, and promote constructive strategies for coping with anger."(p. 351) The task of determining whether an emotion counts as moral in this sense is

\footnotetext{
${ }^{1}$ Recently, Cova and Deonna (2014) have even proposed that a specific emotion (the emotion of "being moved") could directly take values (including moral values) as its intentional object. Thus, one could think there is an even stronger sense of the expression "moral emotion" in which an emotion is moral when it takes as its intentional object a particular value (or disvalue).
}

definitely an evaluative one. It requires distancing ourselves from the framework of everyday interactions and "reactive attitudes" to reflect on the value judgments that our affective reactions embody. ${ }^{2}$

In a fifth and final sense, emotions can be said to be moral or immoral to the extent that their occurrences can be the targets of moral evaluations and agents can thus be praised or blamed on the basis of their emotional responses. At first sight, it may seem odd that our emotional reactions should be states we could be praised or blamed for experiencing: after all, emotions happen to us, they are not things we do or have direct control over. Yet, we do blame people for being happy at funerals or indifferent at the sufferings of others, and we do praise them for feeling ashamed or regretful when they do something wrong. One simple explanation is that we take people's emotional reactions to be indicative of their cares and values, and thus clues to their moral character. ${ }^{3}$ A further question then is whether types of emotions (rather than mere occurrences) can be similarly evaluated? Are there types of emotions whose occurrences always signal some defect in one's moral character? Are there others that always reflect a virtuous trait of character? Love, according to Christian or Hippie moralities, is an example of the latter. "Resentment" (or ressentiment) as Nietzsche describes it is a famous candidate for the former, and so is contempt, an emotion some have understood as necessarily denying the moral value of its target, and thus an emotion bound to violate the duty to respect all persons as moral persons. ${ }^{4}$

As one can see, the expression "moral emotions" is highly polysemous, and each of its different senses raises interesting and puzzling questions about the relationship between emotions and morality. These are the questions the contributions to this topos investigate, in the interdisciplinary spirit characteristic of contemporary research on the sources of morality.

\footnotetext{
${ }^{2}$ For such attempts at assessing the moral value of our emotional reactions from the standpoint of their effects on the whole of society, see for example Strawson (1962) and Nichols (2007). The argument presented here in favor of guilt and to the detriment of shame should not be taken at face value. For a criticism, and more generally for an exposition of the perils attending to the project of praising or blaming emotions for their moral consequences, see Deonna et al. (2011).

3 Thus, one can say that one is responsible for one's emotional episodes in the sense of responsibility understood as "attributability". According to Watson (1996), an agent is responsible for some behavior in the sense of attributability when this behavior discloses something about the nature of the agent's self. For skepticism regarding the very existence of character traits, however, see e.g. Doris (2002).

${ }^{4}$ For a comprehensive discussion of the moral value of contempt, see Bell (2013).
} 


\section{Structure of the Current Topos}

The aim of this collection is to provide the reader with the beginning of a panorama of contemporary research on the relationship between emotions and morality. Because the study of moral emotions ranges over various disciplines, we have included articles from scholars with very different horizons: philosophy, psychology, developmental psychology, sociology, and classics. These papers fall in two different categories: some address general issues surrounding the relationship between emotions and morality, while other focus on particular emotions such as anger, disgust, or gratitude. All papers make the effort of familiarizing readers with the problems and methods of the discipline they belong to, and provide invaluable introductions to the relevant literature.

In the opening article, "Emotions and morality: the view from classical antiquity", David Konstan focuses on the importance of morality for the Greek and Roman understanding of emotions. Drawing on the distinction Greek and Roman philosophers made between human emotions and animal "pre-emotions", Konstan offers a conception of the emotions according to which feeling emotions is essentially tied to the possibility of appraising the world in moral terms, making genuine emotions a human specificity. For example, only humans can be said to feel genuine anger, for only them can understand what constitutes a moral offense.

Next, the concern is with the role emotions play in the formation of moral judgment. In "Moral intuitions and its development: a guide to the debate", Michael Lacewing assesses the role emotions, conceived as a particular type of moral intuitions, play in our abilities as moral agents. Against the thesis that moral intuitions are impervious to all forms of reasoning, Lacewing discusses both Haidt and Narvaez's understandings of moral intuitions and argues that opposing reason and intuition fails to be theoretically fruitful, so long as we do not clarify what these terms exactly cover. On a reasonable understanding of what reason means in the present context, Lacewing shows that its exercise can influence our moral intuitions and eventually shape our moral expertise. Similarly, in "Do emotions play a constitutive role in moral cognition?", Bryce Huebner expresses serious scepticism with regard to the helpfulness of the contrast between the affective and the cognitive. However, his overall claim differs significantly. Focusing primarily on the neuroscientific evidence, he argues that emotions need not play a central role in the formation of moral judgments, and suggests that the current neuroscientific evidence may be more plausibly explained by appeal to predictive and evaluative mechanisms that are neither fully affective nor straightforwardly cognitive.
As we have seen, emotions are not only ways of knowing what one should do: they also motivate us to do the right thing. In "Understanding the moral person: identity, behavior, and emotion", Jan Stets makes use of identity theory to understand how individuals emerge as moral persons and how this status is maintained or challenged in situations. She shows how agents' moral (or immoral) behaviour can be partly explained by what they consider to be their moral identity and how the salience of one's moral identity varies across contexts, such as action versus omissions, thus explaining why our behaviours vary from one situation to the other. How the moral person is formed, and what role emotions play in this process is precisely what Tina Malti and Sebastian Dys investigate in "A developmental perspective on moral emotions". Drawing on the developmental literature on negatively and positively valenced moral emotions in contexts of social exclusion and inclusion, they propose their own developmental model of moral emotions, in which emotions and cognitions about morality get increasingly integrated and coordinated in the course of development.

While emotions are naturally thought of as playing important roles in fostering the welfare of others and society, the possibility that they play this role also for the individuals experiencing them should not be neglected. In their article entitled "Emotions and wellbeing", Christine Tappolet and Mauro Rossi consider the question of whether there is an essential relation between emotion and wellbeing. They distinguish three ways in which emotions and wellbeing might be essentially related - constitutive, causal and epistemic - and offer important reasons to doubt that emotions contribute essentially to wellbeing in any of the relevant senses.

The remaining contributions to this topos set aside the general questions attending to the relations between emotions and morality and focus on particular candidates to the title of moral emotions. In "Anger and morality", Benoît Dubreuil interrogates the ambiguous relations existing between anger and morality: while anger seems to lead to morally regrettable outcomes, it also appears to be one of the chief emotion elicited by our appraisal of moral transgressions. Scrutinizing the literature on anger in both social psychology and experimental economics, Dubreuil shows that there are reasons to doubt that moral outrage or indignation - anger that is sensitive to moral violations-is as widespread as is commonly thought.

In "The role of disgust in norms, and the role of norms in disgust research: why liberals shouldn't be morally disgusted by moral disgust", Jason Clark and Daniel Fessler set out to rehabilitate disgust against those who think that disgust is a morally harmful emotion that should play no role in our moral reasoning. Putting into question 
the idea that disgust must have an exclusive or privileged connection with conservative concerns, they argue that disgust can in fact support certain liberal norms and commitments. They also warn psychologists against the risk of having their political commitments clouding their understanding of disgust.

Finally, the last paper investigates gratitude, an emotion that recently received a lot of attention within positive psychology, in the light of Aristotle's ethics. In "An Aristotelian virtue of gratitude", Kristján Kristjánsson begins by pointing at the conceptual blur that clouds our understanding of gratitude and emphasizes the need for conceptual clarification, starting with the distinction between gratitude as an emotion and as a character trait. $\mathrm{He}$ then draws on Aristotelian ethics to offer a reconstruction of gratitude as an Aristotelian virtue, and connects it with poetic justice.

We think that, taken together, these papers will constitute an invaluable introduction to the multiple ways in which moral emotions are studied. In light of the originality and sophistication of the theses they defend, they will also be of interest to those already versed in the debate. Before we close this introduction and let our contributors speak for themselves, we would like to thank all those who have participated to the International Summer School in Affective Sciences of 2013 on the subject of "Emotion, Morality, and Value". Most of the contributions to this volume stem from exciting presentations and discussions that took place during this event.

Acknowledgments This research was supported by the National Center of Competence in Research (NCCR) Affective sciences financed by the Swiss National Science Foundation (No. 51NF40-104897) and hosted by the University of Geneva.

\section{References}

Bell M (2013) Hard feelings: the moral psychology of contempt. Oxford University Press, New York

Cova F, Deonna JA (2014) Being moved. Philos Stud 169(3):447-466

Damasio A (1994) Descartes's error: emotion, reason, and the human brain. Grosset/Putnam, New York

De Sousa RD (1987) The rationality of emotion. MIT Press

De Sousa R (2001) Moral emotions. Ethical Theory Moral Pract 4:109-126

Deonna J, Teroni F (2012) The emotions: a philosophical introduction. Routledge, New York

Deonna J, Rodogno R, Teroni F (2011) In defense of shame: the faces of an emotion. Oxford University Press, New York

Doris JM (2002) Lack of character: personality and moral behavior. Cambridge University Press, Cambridge

Haidt J (2001) The emotional dog and its rational tail: a social intuitionist approach to moral judgment. Psychol Rev 108:814-834

Haidt J (2003) The moral emotions. In: Davidson JR, Scherer KR, Goldsmith HH (eds) Handbook of affective sciences. Oxford University Press, Oxford

Haidt J (2007) The new synthesis in moral psychology. Science 316:998-1002

Huebner B, Dwyer S, Hauser M (2009) The role of emotion in moral psychology. Trends Cognit Sci 13:1-6

Mulligan K (2008) Moral Emotions. In: Sander D, Scherer KR (eds) Oxford companion to the affective sciences. Oxford University Press, Oxford

Naar H (2013) A dispositional theory of love. Pac Philos Q 94:342-357

Nichols S (2007) After incompatibilism: a naturalistic defense of reactive attitudes. Philos Perspect 21:405-428

Strawson PF (1962) Freedom and resentment. Proc Br Acad 48:187-211

Tangney JP, Stuewig J, Mashek DJ (2007) Moral emotions and moral behavior. Annu Rev Psychol 58:345-372

Tappolet C (2000) Emotions et valeurs. Presses Universitaires de France, Paris

Watson G (1996) Two faces of responsibility. Philos Top 2004:227-248 